\title{
Risco-Brasil: O Efeito-Lula e os Efeitos-Banco Central
}

\author{
Risco-Brasil: The Lula Effect \\ and the Central Bank Effects
}

JOAQUIM ELÓI CIRNE DE TOLEDO*

\begin{abstract}
RESUMO: Este breve artigo discute o comportamento do spread de risco soberano no Brasil desde a adoção de um regime de taxa de câmbio flutuante no início de 99. Os dados apresentados parecem apoiar a hipótese de efeitos perversos da política monetária doméstica sobre o risco-país. Por outro lado, os temores de uma inadimplência futura da dívida provocada por pesquisas de eleição presidencial voláteis - parecem não explicar uma parte significativa do spread de risco, até muito recentemente. O autor está totalmente ciente da existência de uma literatura rica e crescente sobre o risco-país. Este artigo não é uma tentativa de adicionar novas peças de teoria ou evidência analítica rigorosa a essa literatura; seu único objetivo é dar uma pequena contribuição ao debate, apontando alguns fatores geralmente negligenciados que podem explicar o spread de risco soberano do Brasil.

PALAVRAS-CHAVE: Risco Brasil; política monetária; dívida pública.
\end{abstract}

ABSTRACT: This short paper discusses the behavior of Brazil's sovereign risk spread, since the adoption of a floating exchange rate regime in the beginning of 1999. The data presented seem to support the hypothesis of perverse effects of domestic monetary policy on countryrisk. On the other hand, fears of a future debt default — sparked by volatile presidential election polls - do not seem to explain a significant part of the risk spread, until very recently. The author is fully aware of the existence of a rich and fast-growing literature on country-risk. This paper is not an attempt to add new pieces of theory or rigorous analytical evidence to that literature; its sole aim is to make a small contribution to the debate, by pointing at some usually neglected factors that may explain Brazil's sovereign risk spread. KEYWORDS: Brazil risk; monetary policy; public debt.

JEL Classification: E43.

\footnotetext{
* Professor adjunto do Instituto de Economia da Universidade Federal do Rio de Janeiro - IE-UFRJ, Rio de Janeiro/RJ, Brasil. E-mail: cirnedetoledo@gmail.com; Orcid: 0000-0002-7125-4396
} 


\section{INTRODUÇÃO}

O risco-Brasil virou moda. Por isso, era inevitável que se tornasse vítima de definições e análises equivocadas - como é normal acontecer com conceitos técnicos que são vulgarizados. Infelizmente, neste caso, os equívocos são desastrosos, com elevados custos sócioeconômicos e importantes conseqüências políticas para a sociedade brasileira.

Desde já, é preciso apontar três falácias sobre o risco-Brasil: a primeira, de que ele é exclusivamente produzido pelo temor de um calote (explícito ou implícito) da dívida pública; a segunda, de que é uma variável fora do controle do governo, e que só pode ser reduzido por um comportamento "responsável"; e a terceira, de que seu nível elevado e seu aumento recente são devidos exclusivamente às incertezas eleitorais e, em particular, à ascensão nas pesquisas de Luis Inácio Lula da Silva.

Por outro lado, um importante componente do risco-Brasil é simplesmente ignorado pela (quase) totalidade dos analistas: a parcela que corresponde aos efeitos da política monetária seguida pelo governo. Em parte, os juros não são altos porque o risco-Brasil é alto, mas ao contrário: o risco-Brasil é alto porque os juros são altos - aliás, excessiva e equivocadamente altos.

É evidente que as afirmações acima não são óbvias. Para merecerem alguma consideração é preciso construir uma argumentação lógica, bloco a bloco, que nos leve a elas. É o que se fará, na próxima seção, cobrindo os seguintes itens: conceito de risco-país; juros e política monetária; juros futuros e risco-Brasil; componentes de risco; juros internos e externos; percepção de risco e fluxo de capitais; e, finalmente, impactos sobre o câmbio. A última seção do artigo apresenta as conclusões.

\section{O "FRAMEWORK” DE ANÁLISE}

\subsection{Conceito de risco-país}

Deve-se enfatizar que o equivocadamente denominado risco-país não é uma taxa de risco, mas um spread. Ele é definido e calculado pela simples diferença entre duas taxas de juros: a do país, e a dos títulos do governo americano (ambos na mesma moeda), usada como taxa-padrão.

\subsection{Juros e política monetária}

A taxa de juros de um país pode variar sem nenhuma mudança em seu risco efetivo. As taxas de juros de curto prazo subiram e cairam fortemente nos Estados Unidos ao longo dos últimos anos, mas nem por isso nenhum analista tresloucado decretou que houvera aumento ou queda do "risco-EUA". Ou o aumento das taxas de juros nos EUA, ao longo do primeiro semestre de 1999 e de 2000, teria sido devido às incertezas da eleição presidencial e a um "efeito-Gore", indicando que 
os "mercados" avaliavam como pouco confiável e não market friendly o candidato democrata, progressista? E a rápida e significativa queda dos juros após a (demorada e incerta) apuração dos votos, seria devido a um "efeito-Bush", indicando a "grande credibilidade" do republicano, como sempre conservador?

As mudanças nos juros de curto prazo foram atos de política monetária do FED; as mudanças nos juros de longo prazo, por sua vez, refletiram apenas as expectativas sobre o comportamento futuro da própria política monetária. Assim, direta ou indiretamente, tanto os juros de curto como os de longo prazo foram determinados pelo caminho viável esperado da política monetária, como disse Keynes na "Teoria Geral...”. A pergunta, no caso brasileiro, é se mudanças efetivas e/ ou esperadas na política monetária podem afetar os juros dos títulos denominados em dólar, fazendo variar seu spread (o risco-Brasil).

\subsection{Juros futuros e risco-Brasil}

Como demonstrou recentemente o Prof. Affonso Celso Pastore ${ }^{1}$, há sim uma forte correlação entre as taxas de juros de longo prazo - um ano -, no mercado futuro (em reais), e o spread (o risco-Brasil) sobre os títulos denominados em dólar. A conclusão de Pastore é equivocada, porém. Ele argumenta que isso é devido exclusivamente a mudanças no risco, o que é obviamente falso: assim como nos EUA, o comportamento dos juros reflete (pelo menos em parte) o caminho esperado da política monetária, não do risco. E a parcela do risco, que papel pode ter? E como separar todos esses efeitos, na taxa de juros de longo prazo, em reais?

\subsection{Componentes de risco}

Quais riscos podem afetar a taxa de juros (em reais) de longo prazo, no Brasil? São dois, apenas: o risco de calote da dívida pública, e o risco das taxas de juros serem mais altas, no futuro, do que as taxas previstas, impondo assim perdas aos detentores dos títulos pré-fixados (é o chamado risco de mercado).

Considere primeiro o risco de calote. Obviamente, ele tem que se refletir em qualquer espécie de título, mas só poderá ser isolado em um título em reais, que não precise refletir a expectativa dos juros futuros. Esse título existe: é a LFT (Letra Financeira do Tesouro Nacional), cujo rendimento diário é igual ao seu custo (médio) de oportunidade, ou de "carregamento", que é a taxa Selic-referencial, dada pela taxa média de operações compromissadas no mercado de títulos públicos federais. O spread de risco desses títulos, com vencimentos em 2003, 2004, 2005 e 2006 (ou seja, todo o período do futuro governo), era de apenas $0,017 \%$ a.a., $0,023 \%$ a.a., $0,026 \%$ a.a., e $0,027 \%$ a.a., respectivamente, em 28 de fevereiro de 2001 - quando o risco-Brasil era da ordem de 7,50\% a.a.! (Gráfico 1 e Tabela 1). Mesmo agora, quando esses títulos apresentam "risco-calote" de 0,55\% a.a. (2003)

\footnotetext{
${ }^{1} \mathrm{O}$ estudo de A.C. Pastore foi divulgado pelo jornalista Celso Pinto (2002).
} 
e $1,10 \%$ a.a. (2004 a 2006), contra um risco-Brasil de $10 \%$ a.a. (1.000 pontos-base), o risco-calote responde por míseros $10 \%$ do total do spread pago pelo Brasil. E o efeito-Lula? Em fim de agosto do ano passado, o spread da LFT já era de $0,36 \%$ a.a. e, em março de 2002, 0,40\% a.a. Assim, no máximo o efeito-Lula poderia responder por pífios 70 pontos, do total de 1.000 pontos do risco-Brasil. Do início de 2000 até hoje, o risco-Brasil aumentou 350 pontos (de 650 para 1000), dos quais apenas $20 \%$ poderiam ser atribuídos às eleições.

Por outro lado, é sobejamente conhecido no mercado financeiro que o aumento recente no spread das LFTs foi provocado por mudanças na política seguida pelo BC. Em 27 de março deste ano, o Banco Central iniciou as operações de swap cambial, casadas com vendas de LFT. Ao permitir que uma parcela do rendimento da operação, para o investidor, surgisse como spread na LFT (que não era um título demandado pelos investidores que queriam hedge cambial), o Banco Central desestabilizou o mercado, gerando um círculo vicioso que pode ter sérias conseqüências para a estabilidade econômica do Brasil.

O segundo tipo de risco (de mercado) depende da volatilidade das próprias taxas de juros. Dada a relativa estabilidade do risco de calote, no passado, não haveria razão para alteração nesse componente de risco, se as taxas de juros de curtíssimo prazo (efetivas e previstas) não oscilassem. Em outras palavras, esse componente de risco não poderia ter se alterado exogenamente, justificando as significativas oscilações dos juros futuros.

Gráfico 1: Brasil / LFTs - Spreads de Mercado (Vencimentos Selecionados)

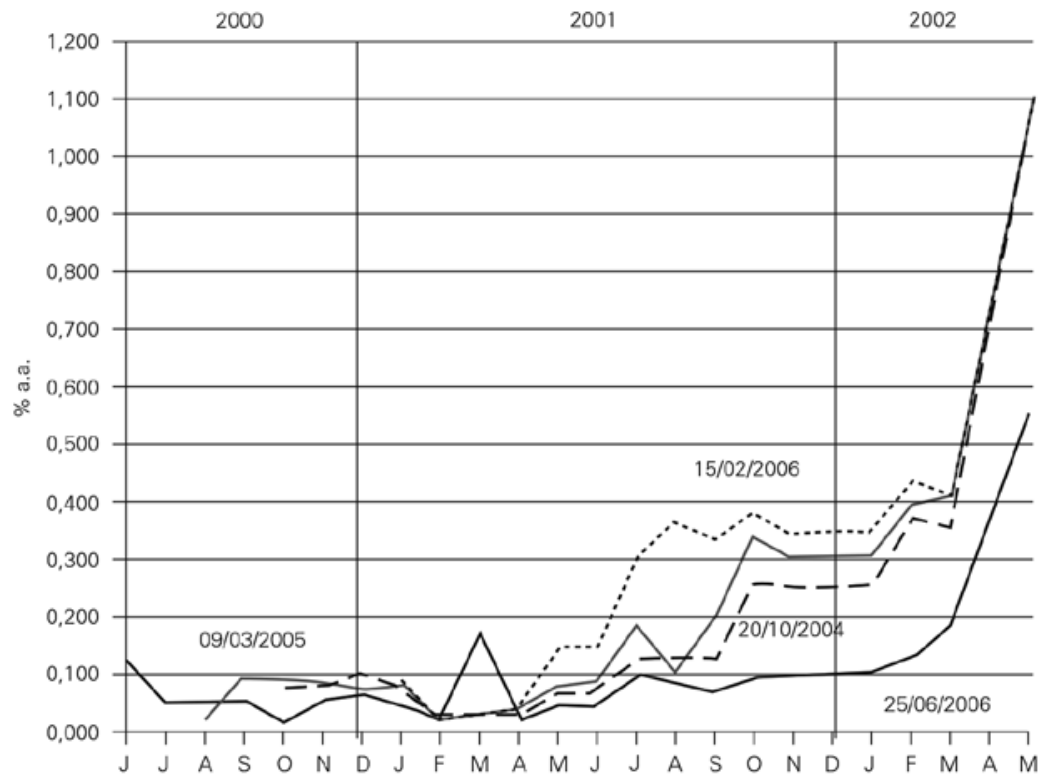


Tabela 1: Brasil / LFTs - Spreads de Mercado (Vencimentos Selecionados)

\begin{tabular}{|c|c|c|c|c|}
\hline Data & $25 / 06 / 2003$ & $20 / 10 / 2004$ & 09/03/2005 & $15 / 02 / 2006$ \\
\hline $31 / 05 / 2000$ & 0,067 & & & \\
\hline $30 / 06 / 2000$ & 0,120 & & & \\
\hline $31 / 07 / 2000$ & 0,050 & & & \\
\hline $31 / 08 / 2000$ & 0,050 & & 0,016 & \\
\hline 29/09/2000 & 0,051 & & 0,089 & \\
\hline $31 / 10 / 2000$ & 0,018 & 0,072 & 0,090 & \\
\hline $30 / 11 / 2000$ & 0,052 & 0,079 & 0,086 & \\
\hline $28 / 12 / 2000$ & 0,059 & 0,095 & 0,076 & \\
\hline $31 / 01 / 2001$ & 0,046 & 0,079 & 0,078 & 0,086 \\
\hline $28 / 02 / 2001$ & 0,017 & 0,023 & 0,026 & 0,027 \\
\hline $30 / 03 / 2001$ & 0,169 & 0,022 & 0,026 & 0,030 \\
\hline $30 / 04 / 2001$ & 0,017 & 0,025 & 0,034 & 0,041 \\
\hline $31 / 05 / 2001$ & 0,044 & 0,062 & 0,076 & 0,141 \\
\hline $29 / 06 / 2001$ & 0,040 & 0,069 & 0,083 & 0,141 \\
\hline $31 / 07 / 2001$ & 0,100 & 0,126 & 0,183 & 0,301 \\
\hline $31 / 08 / 2001$ & 0,082 & 0,128 & 0,097 & 0,361 \\
\hline $28 / 09 / 2001$ & 0,067 & 0,122 & 0,200 & 0,331 \\
\hline $31 / 10 / 2001$ & 0,090 & 0,258 & 0,333 & 0,380 \\
\hline $30 / 11 / 2001$ & 0,092 & 0,247 & 0,300 & 0,338 \\
\hline $31 / 12 / 2001$ & 0,099 & 0,250 & 0,300 & 0,347 \\
\hline $31 / 01 / 2002$ & 0,102 & 0,249 & 0,300 & 0,342 \\
\hline $28 / 02 / 2002$ & 0,128 & 0,370 & 0,387 & 0,428 \\
\hline $28 / 03 / 2002$ & 0,179 & 0,352 & 0,401 & 0,401 \\
\hline $30 / 04 / 2002$ & 0,386 & 0,681 & 0,689 & 0,704 \\
\hline $24 / 05 / 2002$ & 0,550 & 1,100 & 1,100 & 1,100 \\
\hline
\end{tabular}

Pode-se argumentar, equivocadamente, que o aumento dos juros futuros estaria refletindo o risco de calote implícito, via inflação. Isso seria errado considerar por duas razões: primeiro, o estudo do prof. Pastore iniciou-se em 31/8/1999, cobrindo quase todo o segundo governo FHC; não é razoável supor que, nessa época, houvesse tal temor, como são provas contundentes as expectativas de módica inflação na época, coletadas e divulgadas pelo Banco Central (Tabela 2); segundo, a inflação facilitaria a solução dos problemas fiscal e externo, como se viu em 198385, reduzindo o risco dos títulos em dólar. 
Tabela 2

\begin{tabular}{ccccc}
\hline & \multicolumn{4}{c}{ Projeções de Índices de Preços - 24/08/2001 } \\
\hline \multirow{2}{*}{ Índices } & Ago & Set & 2001 & 2002 \\
\cline { 2 - 5 } & 1,00 & 0,50 & 9,04 & 5,50 \\
IGP-DI & 1,26 & 0,55 & 8,97 & 5,50 \\
IGP-M & 1,10 & 0,40 & 6,30 & 4,40 \\
IPC-FIPE & 0,65 & 0,40 & 6,90 & 4,50 \\
INPC & 0,70 & 0,40 & 6,32 & 4,50 \\
IPCA & Projeções de Índices de Preços - 24/05/2002 & \\
\hline & & Pesquisa do BC & \\
\hline Índices & Mai & Jun & 2002 & 2003 \\
\hline IGP-DI & 0,55 & 0,65 & 5,66 & 4,73 \\
IGP-M & 0,54 & 0,55 & 5,57 & 4,60 \\
IPC-FIPE & 0,19 & 0,40 & 4,39 & 4,00 \\
INPC & 0,40 & 0,40 & 6,13 & 4,25 \\
IPCA & 0,40 & 0,37 & 5,46 & 4,00 \\
\hline
\end{tabular}

O que se pode afirmar, assim, é o que os agentes econômicos sempre souberam: os juros futuros, no Brasil, assim como nos EUA, têm basicamente refletido apenas a expectativa de política monetária e não aspectos de risco. Como é possível que a política monetária interna do $\mathrm{BC}$, em reais, afete os juros externos, em dólares? Não seria isso um absurdo para a teoria econômica?

\subsection{Juros internos e externos}

A relação entre juros internos e externos é determinada por dois fatores. Primeiro, como é evidente, os juros sobre os títulos denominados em dólar, no Brasil (como as NTN-Ds), e os dos títulos transacionados externamente (como os Cbonds, os Globals etc.) tendem a ser equiparados. Isso ocorre devido à arbitragem, possibilitada pela livre movimentação de capitais. Segundo, a volatilidade da taxa de câmbio (Gráfico 2) faz com que o custo do hedge (ou a expectativa de desvalorização) seja relativamente estável — ainda que elevado. Assim, quando sobem os juros futuros em reais, sobem junto os juros em dólares, aumentando seu spread (ou o risco-Brasil). O que explica, porém, que não haja uma inundação de capitais na economia, atraídos pelos juros mais altos? A resposta é a percepção de risco. 


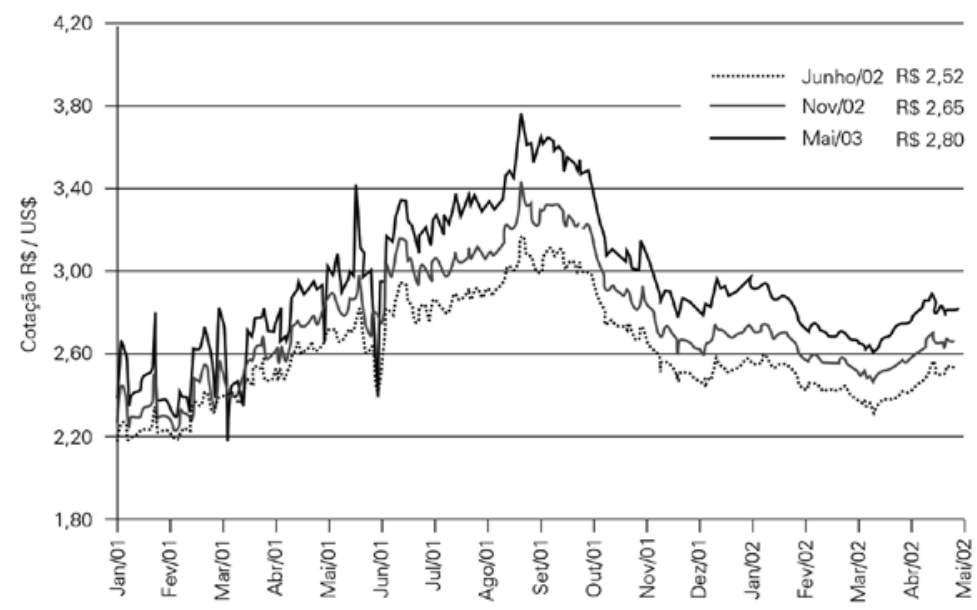

\subsection{Percepção de risco e fluxos de capitais}

$\mathrm{Na}$ impossibilidade prática de mensurar corretamente o verdadeiro risco de um país, que é uma entidade sócio-econômico-política de absoluta complexidade, e na ausência de padrões históricos e estáveis para as taxas de juros, os investidores externos agem como nós: ou seja, equivocadamente interpretam um aumento do spread pago pelo Brasil como um aumento de risco. Como uma coisa compensaria a outra, não há razão para os juros altos atraírem capitais.

As respostas dos mercados financeiros, na divulgação da recente decisão de manutenção dos juros pelo BC (em maio), comprovam a análise acima. Como alguns agentes econômicos esperavam uma (pequena) redução nos juros, sua manutenção produziu um (pequeno) aumento nas taxas futuras de juros. Quando este autor viu o anúncio, imediatamente concluiu que o risco-Brasil subiria $-\mathrm{e}$ foi exatamente o que ocorreu. Também concluiu que o câmbio subiria - e, mais uma vez, acertou. Mas por que se desvalorizaria o real, com juros maiores? Isso não é um contra-senso?

\subsection{Impactos sobre a taxa de câmbio}

Como se viu, juros mais altos em reais aumentam os juros em dólar, ampliando o spread - o risco-Brasil, não gerando entradas de capitais que tendessem a valorizar o câmbio. Por outro lado, o aumento do spread-Brasil é incorporado nas avaliações de empresas e investimentos no país, desvalorizando-os. Logo, tende a reduzir os fluxos de investimento direto externo (IDE), sinalizando e produzindo uma pressão de desvalorização cambial (Gráfico 3). 


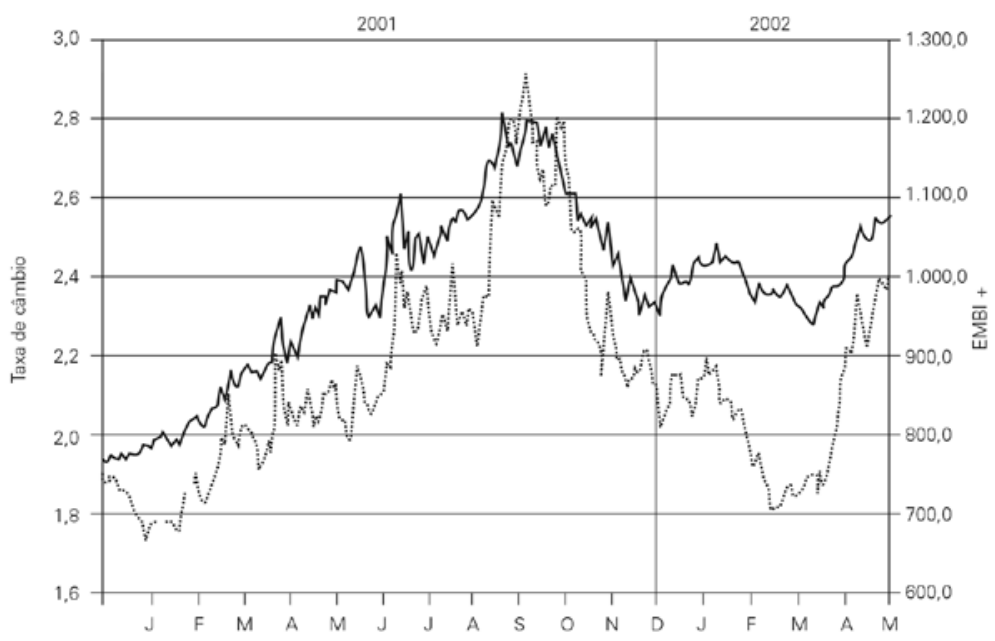

Nota: o risco-país é calculado pelo banco JP Morgan e mede em centésimos de pontos percentuais (os chamados pontos-base) o prêmio sobre os juros de títulos brasileiros no exterior na comparação com papéis do Tesouro norte-americano.

\section{CONCLUSÕES}

Além dos pontos levantados, claro, é preciso adicionar o risco efetivo produzido por juros altos, que reduzem a probabilidade de atingimento das condições de estabilidade econômica de longo prazo, dadas pelas trajetórias da dívida pública, do passivo externo líquido, e do crescimento do PIB. Juros altos reduzem o crescimento e, ao mesmo tempo, aumentam os custos desses passivos, requerendo maiores superávits primários (inclusive externos), que têm custos econômicos - incluindo os inflacionários - , sociais e políticos. ${ }^{2}$

É evidente, por outro lado, que não se pode baixar os juros a zero (!), nem mesmo aos níveis de países estáveis, como os EUA. Os juros têm componentes conjunturais e estruturais. Em qualquer país, se há pressões salariais (e de margens de lucro, de preços de matérias-primas etc.), gerando pressões inflacionárias, os juros serão conjunturalmente altos - como nos EUA, até a explosão da bolha especulativa das ações. Em qualquer país, se há instabilidade institucional, desrespeito a contratos e direitos de propriedade etc., os juros serão estruturalmente altos — e, claro, alta também será a taxa de lucro, enquanto os salários reais serão baixos.

\footnotetext{
${ }^{2}$ Os efeitos perversos dos juros sobre a sustentabilidade da dívida pública e, logo, sobre o risco-país têm sido objeto de análise do presente autor desde o início do Plano Verão (veja alguns exemplos nas referências bibliográficas).
} 
Não se pode usar a análise aqui apresentada, por outro lado, para defender políticas fiscais irresponsáveis, ou a "dominância fiscal". O ponto é outro: os juros devem ser os menores possíveis; e deve-se gerar pelo menos o superávit primário requerido para obter uma trajetória sustentável da dívida pública. Aliás, se possível, o superávit primário deveria ser maior do que esse nível, viabilizando a redução da relação dívida pública/PIB ao longo do tempo, assim reduzindo a pressão sobre os mercados de ativos e, assim, viabilizando juros ainda menores. Por outro lado, não é correto afirmar que os juros internos só poderão cair, quando cair o risco-Brasil - pois, nesse caso, eles nunca cairão!

Se a análise acima estiver correta, ela tem importantes implicações práticas para a condução da política monetária no Brasil. A política monetária deve ser conduzida com muita cautela, sem juros excessivamente elevados, que contaminam por múltiplos canais a percepção de risco-país e o custo do capital externo. Infelizmente, é essa a situação atual. O Brasil está em recessão, com desemprego elevado e salários nominais crescendo a um ritmo extremamente bem-comportado, abaixo de $3 \%$ a.a. Os salários são os preços fundamentais da economia, pois são os custos básicos. Eles é que devem ser o objeto da meta de inflação, explícita ou implicitamente (como é o caso dos EUA). É absurdo querer compensar a inflação dos preços administrados e do câmbio, através do agravamento ainda maior do desemprego, para controlar o que já está controlado — os salários. Os juros podem e devem cair - gradualmente, claro, mas sem mais delongas.

Não se pode culpar as eleições, ou o Sr. Luís Inácio Lula da Silva, pelo riscoBrasil. Ao invés de "mandar prender os suspeitos de sempre", parece ser muito mais frutífero analisar as políticas macroeconômicas brasileiras, para aumentar sua eficiência.

Chega de política monetária equivocada. Que volte o bom senso ao Banco Central, e o país aliviado o aplaudirá, como nos dois primeiros anos da atual gestão.

\section{REFERÊNCIAS BIBLIOGRÁFICAS}

PINTO, C. (2002). "O risco não existe só em Wall Street”. Folha de S. Paulo, maio 23, 2002: A-10.

CIRNE DE TOLEDO, J.E. (1988). "Dívida, juros, déficit e inflação”. Seminário sobre Inflação e Política de Estabilização: Brasília, novembro 1988.

. (1989). “O erro dos juros no Plano Verão”. Folha de S. Paulo, março 1989.

. (1998). "Brasil, a bola da vez?”. Economia Aplicada, outubro-dezembro 1998: 739-742.

. (1999). "Políticas Econômicas e Estabilização no Plano Real”. Economia Aplicada, março

1999: 61-77.

. (2002). "Juros altos: Custos sem Benefícios”. Folha de S. Paulo, abril 8, 2002: B-2. 